Western University

Scholarship@Western

Western Libraries Publications

Western Libraries

$3-2013$

\title{
Undergraduate Program Review Processes: A Case Study in Opportunity for Academic Libraries
}

John Costella

University of Western Ontario, jccostel@uwo.ca

Tom Adam

University of Western Ontario, tadam@uwo.ca

Fran Gray

University of Western Ontario, fgray@uwo.ca

Nicole Nolan

University of Western Ontario,nnolan@uwo.ca

Catherine Wilkins

University of Western Ontario, cwilkin8@uwo.ca

Follow this and additional works at: https://ir.lib.uwo.ca/wlpub

Part of the Library and Information Science Commons

Citation of this paper:

Costella, John; Adam, Tom; Gray, Fran; Nolan, Nicole; and Wilkins, Catherine, "Undergraduate Program Review Processes: A Case Study in Opportunity for Academic Libraries" (2013). Western Libraries Publications. 36.

https://ir.lib.uwo.ca/wlpub/36 


\section{Undergraduate Program Review Processes: \\ A Case Study in Opportunity for Academic Libraries}

\section{Corresponding Author}

John Costella

Research and Instructional Services Librarian

Allyn \& Betty Taylor Library

University of Western Ontario

London, Ontario N6A 5B7

Phone: 519-661-2111 x80961

Fax: 519-661-3435

jccostel@uwo.ca

Tom Adam

Teaching and Learning Librarian

Western Libraries

University of Western Ontario

London, Ontario N6A 3K7

Phone: 519 661-2111 x81441

tadam@uwo.ca

Fran Gray

Research and Instructional Services Librarian

The D. B. Weldon Library

University of Western Ontario

London, Ontario N6A 3K7

Phone: 519 661-2111 x89219

fgray@uwo.ca

Nicole Nolan

Research and Instructional Services Librarian

C. B. "Bud" Johnston Library

University of Western Ontario

London, Ontario N6A 3K7

Phone: 519-661-2111 x80958

nnolan@uwo.ca

Catherine Wilkins

Assistant University Librarian

The D. B. Weldon Library

University of Western Ontario

London, Ontario N6A 3K7

Phone: 519 661-2111 x84772

cwilkin8@uwo.ca 


\section{UNDERGRADUATE PROGRAM REVIEW PROCESSES: A CASE STUDY IN OPPORTUNITY FOR ACADEMIC LIBRARIES}

\section{$\underline{\text { ABSTRACT }}$}

How can an academic library most effectively participate and expand their contributions to program reviews at the institutional level? By becoming involved in undergraduate reviews, college and university libraries can articulate new and enhanced roles for themselves on campus. Academic libraries have always contributed to a variety of institutional review processes. However, by embracing a more holistic view of its support, the library can expand beyond collection-related metrics to encompass all the ways the library interconnects with the program. Furthermore, by becoming proactively involved with the committee(s) responsible for managing institutional program reviews, libraries can contribute to the governance of this essential activity on campus. This paper describes one academic library's experience and efforts in becoming involved with undergraduate reviews at both the program and institutional levels. It is hoped that sharing our case study and the tools we have created, will benefit other academic libraries.

\section{INTRODUCTION}

The globalization of higher education has reached a crossroads. As we approach the universal university and the resulting portability of degrees and credits, countries around the world are examining existing processes of accreditation and accountability. They are establishing or revisiting frameworks for quality assurance in order to ensure graduating students at all levels have an equal opportunity on the global stage. Defining standards and guidelines that can inform the evaluation of student achievement, as well as appraise programs and curricula is a major challenge for universities. At the same time however, potential opportunities arise, especially for academic libraries. Although there is abundant evidence about why academic libraries need to accommodate institutional or accrediting body requirements, there is a paucity of literature that addresses the process through which libraries respond to these demands. 
This case study will focus on the University of Western Ontario (Western), in London, Ontario, which is a major research intensive institution in Canada. Western Libraries serves the university's diverse population of over 35,000 FTE students, 75\% of which are undergraduates, and contributes to the teaching and research of over 1,400 faculty members. Spread across campus, and consisting of eight separate service points, Western Libraries employs a liaison model for delivery of teaching and research support. Research and Instructional Services (RIS) Librarians build collections, answer in-depth reference questions, and instruct in their area of expertise. They also are the primary conduit between the library and Western's 65 Faculties, Departments and Professional Schools.

In this paper, we address how libraries can most effectively participate and expand their contributions to program reviews at the institutional level. This will be accomplished first by exploring the literature and providing some background information on program reviews, and the cultural shift occurring around program assessment. This is followed by a detailed accounting of how one academic library has integrated successfully into the undergraduate program review process at a Canadian university. Next, we explain how academic library involvement benefits five stakeholders: universities, libraries, programs, librarians, and students. Finally, we provide recommendations for other academic libraries when considering integration into a program review process.

\section{LITERATURE REVIEW}

Library support has always been recognized to some extent in the assessment of academic programs and institutions. A number of papers have addressed academic 
library involvement with program reviews in different countries. Salvesen describes the situation in Norway and raises questions about the measurement criteria a library needs to use to identify potential for improvement. ${ }^{1}$ DeJager indicates that in South Africa, libraries were hardly even considered in quality assurance schemes until 2004 when academic librarians collaborated to develop criteria, standards and models that they could use in their own self-assessments of university libraries. ${ }^{2}$ Ubogu and Walker describe their institution's response to the South African quality audits at the University of the Witwaterstrand in Johannesburg. ${ }^{3}$ To collect evidence that their library was meeting the needs of its users, they compiled a Library Framework Document which articulated seven evaluation criteria. Adebayo describes the implications of quality assurance programs for academic libraries in Nigeria. ${ }^{4}$ Garner and Tang detail the quality assurance and benchmarking framework that has been developed at Curtin University Library in Australia. Their program is based on a planning framework and a performance framework which include regular continuous improvement reviews and the collection of quantitative data that is used for benchmarking. ${ }^{5}$

The library literature also offers research describing the transition from traditional performance measurement methods to a more user-based perspective and its impact on library services. Lakos and Phipps articulate the need for libraries to develop a 'culture of assessment' in which "processes and services are continuously evaluated and considered in light of customer expectations" ${ }^{\prime 6}$. Weiner investigates the relationship between traditional quantitative measures of library quality (e.g. number of reference transactions) with the more qualitative indicators such as assessment of information literacy competency. She found that there is a relationship between the traditional measures and overall user satisfaction. ${ }^{7}$ The link between learning outcomes and the 
provision of information literacy instruction is explored by Saunders who describes the implementation of the Middle States Commission Information Literacy Framework. ${ }^{8}$ Both the education literature and the library literature provide ample evidence of a significant shift in the understanding of how higher education is measured and evaluated, as well as in the nature of the relationship between the academic library and its parent institution.

The literature offers considerably less evidence describing and operationalizing the role of academic libraries in institutional program review processes. Gregory used interviews and questionnaires to gather information on academic library involvement in program review processes across a number of States. Although the work concentrated mainly on support for new programs, Gregory found a tremendous variance in the input documentation, ranging from simple short statements to elaborate evaluations of library holdings and budgetary information. ${ }^{9}$ In 1992 , Kuo described a model of support for program reviews adopted at Ball State University at the request of the Indiana State Commission. ${ }^{10}$ The paper described how the model was implemented and the support available to the librarians charged with creating the documentation for the Commission; however, the Ball State model focused primarily on quantitative collections criteria rather than the more holistic view of library support that drives current assessment models.

\section{CULTURAL CHANGE}

Universities are undergoing major transformational change, as a result of enrolment growth, internationalization, and emphasis on quality assurance. Indicative of escalating campus populations is the assertion by the Association of Universities and Colleges in Canada (AUCC) that the number of full-time university students in Canada 
has more than doubled since 1980. ${ }^{11}$ Internationalization within the Canadian context includes attracting international students, providing Canadians with international experiences, and improving diversity and the international experience on campus. ${ }^{12}$ Finally, the greater emphasis on quality assurance in higher education is an indicator of the developing culture of assessment. ${ }^{13}$ Fostering a culture of assessment is essential in order to compete globally, ensure quality graduates, contend with rapid enrolment growth, and have a reputation for excellence. Institutions of higher education are now mandated "to implement explicit learning outcomes and assessment policies"14.

Involvement with the program review process gives academic libraries an exciting opportunity to be a part of a cultural change within the university. Furthermore, early integration into the review process enables improved communication, builds stronger ties to facilitate knowledge sharing, and provides new avenues for the library to promote its value across campus. According to the Association of College and Research Libraries' Joint Statement on Faculty Status of College and University Librarians, "Because the scope and character of library resources should be taken into account in such important academic decisions as curricular planning and faculty appointments, librarians should have a voice in the development of the institution's educational policy". ${ }^{15}$ In his survey of academic business librarians and their perceptions of the accreditation process, White identified that the lack of appropriate documentation and the need for more communication, especially with faculty, were key concerns of the librarians surveyed. ${ }^{16}$ Budd reinforces the value of faculty - library communication by stating that "It is indubitable that learning and critical thinking depend upon exposure to and evaluation of the products of multiple minds. Librarians' contributions to such critical learning can be 
great but only as a systemic, consistent, and timely connection is made with faculty.

Success at all types of institutions requires the close cooperation of faculty and librarians. ${ }^{17}$ Library involvement in institution-wide planning and review processes can address some of those concerns. "While libraries have grappled with environmental changes before, never before have the changes been so dramatic and sweeping as they are now" 18 . In order to ensure their viability on campus, academic libraries, in addition to responding to changes occurring at the institutional level, must evolve to reflect changes within the library profession. ${ }^{19}$ The role of libraries is shifting; the importance of some of the traditional roles within academic libraries is decreasing, while new roles are emerging. ${ }^{20}$ Libraries may feel threatened by this shift in their changing role. ${ }^{21}$ Communication must occur in order to promote a culture that can thrive in change. ${ }^{22}$ By using multiple channels of communication, libraries can interact with their stakeholders, becoming more visible and fostering allies on campus. ${ }^{23}$ If libraries are a structured and expected part of the program review process, then they can build bridges, and promote communication. We suggest that library participation in the undergraduate review process can help libraries succeed with managing these cultural shifts by facilitating communication, and improving alignment with the institutional strategy.

The communication promoted through involvement with the undergraduate review process can help modify attitudes about the libraries' relevance, especially in light of the surfeit of information freely available online. Who hasn't heard a student say, "I'm just going to Google it" when referring to finding information for an academic project? Unfortunately, this attitude also seems to permeate through to administration. Senior administrators have claimed, "I don't believe we need libraries"24. The ties forged during 
the undergraduate review process will facilitate communication about how the library is managing environmental change and staying relevant, thereby helping with library promotion and marketing.

\section{THE CASE STUDY}

In Canada, education is provincially mandated. Recently Ontario has made significant inroads into consolidating quality assurance processes under a single umbrella, the Quality Assurance Framework, regulated by the Ontario Universities Council on Quality Assurance, under the auspices of the Council of Ontario

Universities. ${ }^{25}$ In anticipation of this mandated quality assurance process, Western Libraries seized the opportunity to become involved in program reviews from the outset. The libraries and their staff have become active participants at both the institutional level as well as within the library system itself. First, the library has representation on the Senate Subcommittee on Program Review - Undergraduate (SUPR-U) that oversees undergraduate program reviews. The result of this participation is that the library is aware of each program review as it arises, and therefore ensures our involvement with each of these reviews. Second, we have developed a template with guidelines to help librarians responsible for preparing and writing the library component of the review. The guidelines help to interpret and utilize the template effectively. The template and guidelines also expedite the writing process, define expectations about what should be in each review, and promote consistency of reports across disciplines.

\section{Planning the Process: The Undergraduate Program Review Working Group}

In 2008 the University of Western Ontario established the Senate Subcommittee for Undergraduate Program Review (SUPR-U). At Western, it is common practice that 
when a standing committee is struck the University Librarian or designate is included in its membership. In the fall, the SUPR-U designate issued a call for members across Western Libraries to establish the Undergraduate Program Review Working Group. Its mandate was to develop a process for members by the Western Libraries representative on the Senate Subcommittee on Program Review - Undergraduate (SUPR-U designate), with a mandate to develop a process for Western Libraries' involvement in undergraduate program reviews. The group reported to the Management Committee of Western Libraries, which includes the University Librarian in its membership, and this committee was responsible for granting final approval on the Working Group's proposed process. From the outset, our objective was to create a mechanism that would allow for consistent and efficient production of library documentation in support of these reviews. In the following sections, we explain how we planned the process, describe the guidelines and template, and outline how we put our review process into action.

Within the working group's membership, there was representation from across Western Libraries, including a library administrator, the Teaching and Learning Librarian, and several Research and Instructional Services (RIS) Librarians. We realized that the new process had to be not only effective but also flexible enough to accommodate the diversity and complexity of our institution. As already pointed out in the literature review, there were very few studies from which to draw examples. Alternatively we examined locally available library review documentation that was prepared in support of other review requirements including graduate programs, accreditations, and departmental reviews. In our examination of other library review documentation, we considered the differences and similarities in content between the available reviews and potential undergraduate program reviews. We found that the 
content of the reports was generally dependent on the nature of the report and the requesting body.

As a result of the examination of our existing documentation, the committee decided to create a template for librarians to use. Following input and final approval from Western Libraries' administration and colleagues, via the Management Committee, the template entitled "Report on Western Libraries' Support for Program X" was produced and the full version is available online. ${ }^{26}$ To facilitate the use of the template, we created guidelines which provide further description of each section and offer suggestions for possible content. Librarians have the flexibility to employ those suggestions as appropriate for a particular program. The guidelines are also available online. $^{27}$

Upon acceptance of the final guidelines and template, the committee then proposed a process for librarians to follow from initial request to final delivery of the library documentation. First, Western Libraries is notified about an upcoming program review through the SUPR-U designate, who then contacts the appropriate Director or Head within Western Libraries. At that point, the Head/Director will identify a librarian to create the report. Following approval of the report at the authoring Library level, the RIS Librarian submits the report to the SUPR-U designate for further review and approval from Western Libraries administration. Finally, the SUPR-U designate forwards the completed report to the department affiliated with the program and a copy sent back to the authoring Library Unit to close the communication cycle. The Office of the University Librarian maintains the official file of the final library reports for all program reviews. 


\section{The Guidelines and Template}

The challenge was to create a tool that would be functional across all subject disciplines, yet flexible enough to allow for customization of the report to specific programs. Flexibility was ensured through the use of placeholders to indicate where librarians can insert program specific information. An example of a placeholder can be seen in the following passage from the template:

"Undergraduates in Program $X$ not only have access to all the resources of Western Libraries, but are specifically supported by Library $Y$. [Include specifics about the "home" library which supports the program.]"28

The functionality of the template is further enhanced by the alignment of the guidelines with sections of the template.

The template consists of 6 sections:

- Review Summary and Future Directions

○ Introduction

$\circ$ Teaching and Learning

○ Collections Support

- Collaboration and Communication

○ Services

With the exception of the Review Summary and Future Directions and the Introduction, the sections parallel the major roles and responsibilities of librarians within Western Libraries.

The Review Summary and Future Directions section discusses the library's contribution to the success of the program. It explains plans for maintaining current levels of support or rectifying identified deficiencies. It also considers emerging trends or 
technologies that may impact the program. The librarian creating this document has the option of adding library specific statements as appropriate.

The Introduction features a standard text. It includes descriptive information about Western Libraries, and outlines the function of the report and the mandate under which the report is created.

Each of the following four sections of the template shares a similar structure. We provide standard text that applies across Western Libraries. This text is supplemented with placeholders that alert the author to include possible program-specific content. The accompanying guidelines offer suggestions for the types of activities that would be useful to report in each section.

The Teaching and Learning section emphasizes the alignment between the Undergraduate Degree Level Expectations and the ACRL Information Literacy Standards. The Collections Support section highlights collections management policy, acquisition of subject specific resources, collection metrics if available, and consortial arrangements which impact on resources for that subject. The Collaboration and Communication section focuses on liaison activities such as creating course specific guides, attending departmental meetings and contributing to curriculum committees. The Services section of the report describes support for students in the program including self-serve functions, additional facilities, and access to technology.

\section{Putting the Review Process into Action}

We have had experience with the new process through four academic cycles. At Western the academic cycle, or academic year, spans from July $1^{\text {st }}$ of one year to June $30^{\text {th }}$ of the next. The template and guidelines have been used successfully across all faculties associated with Western and have also been used by our Affiliated University 
College Libraries. As well as preparing and submitting the report, several librarians and the SUPR-U designate had the opportunity to meet with reviewers as part of the process. This is valuable because it encourages dialogue about the impact of the library on the undergraduate program and provides a forum for gathering information and discussing ideas for future consideration. Further proof of the acceptance of our process within the institution comes from the fact that in their Guidelines for the Appraisal of Undergraduate Programs, SUPR-U includes the Library Report as an integral part of the documentation to be submitted in a program review. . ${ }^{29}$

\section{Workload Implications}

As much as the use of the guidelines and template expedites the review process for librarians, there are still workload implications that must be considered. Although the primary workload impact is on the librarian designated to create the report, input from others may be required. For example, technical staff might contribute by generating library statistics relevant to the program. In the case of interdisciplinary subject areas, it will be necessary to collaborate with colleagues to ensure that all relevant disciplines supporting the interdisciplinary program are adequately represented in the report. Finally, the review and approval of the final report involves representatives of library administration.

Western Libraries RIS Librarians have found using the template and guide useful. These tools articulate what Western Libraries expects of program reviews. They streamline the process and increase the quality and consistency of the reports. Librarians who have been involved in program reviews have said that the template and guide provide focus and structure. Furthermore by supplying a common language, they reduce the amount of time necessary to complete the review. 
Based on feedback from RIS Librarians, we have made revisions to the original tools to reflect changes in our collections and service strategies. The revised document is more concise and flexible, enabling greater latitude for librarians to incorporate program specific information. This revised document will be released fall 2012.

\section{HOW THE STAKEHOLDERS BENEFIT}

We have identified five stakeholders: universities, libraries, programs, librarians and students, for whom library involvement in the review process is of value.

\section{Universities: Consistent High Quality Reviews}

When academic libraries are systematically engaged with the university program review process, the resulting library documentation will be of high quality and consistent across programs. If the institution has governance in place that facilitates the universitylibrary program review relationship, each subject librarian will be formally embedded into the review process. Expectations about what is in the library component of the review will be specified, thereby improving the overall quality and consistency of the documents across programs. Further, as an academic partner in the review process, the library is aligned with the strategic directions of the University and connected with the institution in fulfilling its research and teaching mission.

\section{Libraries: Enhancing the Library Profile}

Taking a holistic approach to library contribution in programs, by highlighting collections, services and instruction that the library offers for specific courses or programs, results in increased awareness of the library's role on campus. The wider 
community is exposed to concrete examples of how the library contributes to student success. It also communicates how the library enhances the teaching and learning environment through the resources it collects, the services it offers and the learning opportunities it creates in classrooms and labs on campus.

\section{Programs: Quality Control}

For programs, the major benefit of including the library in the review process is quality control. Reviewing library involvement in programs can lead to quality improvements in all areas where the library provides support, as well as reveal gaps or opportunities for the library to enhance resources and services. Aligning library participation with the institutional cycle of program reviews provides an added level of insurance that there is a regular and systematic assessment of library contribution to programs. In a time when the value of library services and resources is no longer universally recognized, regular review of the resources and services provided to support each program is crucial to ensure that librarians continue to be responsible stewards of library assets.

\section{Librarians: Liaison and Assessment Opportunities}

Greater participation in program reviews has several benefits for academic librarians. It builds relationships by offering librarians an opportunity to interact more closely with faculty members. Secondly, reviews provide a formal mechanism enabling librarians to evaluate the support they provide for the program. Further, information gathered during the review can aid in collection management and development activities. 
Finally, engaging in the review process can reveal strengths in the instruction program as well as opportunities for growth.

\section{Students: Targeted Services and Program Aligned Resources}

The creation of library documentation for program reviews requires the authoring librarian to take inventory of the services and resources currently available to students in the program. In addition, the review can identify library services and resources needed to foster student success. The ramification is that future students could have a wider variety of services and access to more relevant resources.

In summary, all stakeholders will benefit from library involvement in the review process. Academic libraries must explore avenues that foster and enhance engagement in institutional review initiatives. Finally, libraries must develop processes that result in consistent high quality documentation in support of program reviews.

\section{RECOMMENDATIONS FOR OTHER ACADEMIC LIBRARIES}

In previous times, librarians have been involved with program reviews; however, involvement was often inconsistent and not well defined. As Kuo points out, "This proactive approach is an improvement over the past when last minute requests for complex support data were most frequent and matter of fact ${ }^{\prime 30}$. We suggest that the library's involvement with program reviews must be purposeful, deliberate, and nurtured. The process must be legitimized so that library involvement in the review process is expected and the norm. Ties created from this process can facilitate communication, to ensure the resources and services are aligned with the university's needs. 
We believe that others can benefit from our experience. Most importantly, we recommend that other libraries make use of our template and guide. We have acquired a Creative Commons License that allows use and modification of our documents with attribution.

Next, we recommend, as much as possible, that libraries implement both topdown and bottom-up processes. It is important that libraries investigate the infrastructure in place for program review within the institution and identify areas where the libraries could fill a role. In this context a top-down approach would secure library representation on groups or committees tasked with this function. Specifically, we have library representation on the university level committee that oversees program reviews. This representation ensures open communication between the university and the library. Because of this involvement, librarians have a voice in influencing institutional processes.

In addition to formal top-down approaches, we recommend implementing bottomup processes to ensure the reviews go smoothly by making it easier for librarians to contribute to the program review. As with any new initiative, librarians may feel apprehensive about the new process. This apprehension may be intensified when there are no pre-existing models to emulate. The challenge may be compounded for new or interdisciplinary programs. In our experience, having resources like our guide and template reduces this apprehension because they clearly identify important areas to consider for the review, and help articulate expectations. They also ensure reviews are consistent, efficient, and of high quality.

\section{Conclusion}


Becoming embedded into program review processes creates opportunities for academic libraries to engage in institution-wide governance. It allows librarians to be proactive in developing library-specific procedures that ensure the delivery of consistent and high quality library documentation.

In our context, integration into the institutional process of undergraduate program reviews has afforded tremendous opportunity for Western Libraries. It provides an avenue for communication between the university and the library system. With our combined top-down and bottom-up approach all stakeholders, including the university, libraries, programs, librarians, and students benefit. Although not the only means used by Western Libraries in assessing its resources and services, the program reviews provide another mechanism to ensure periodic examination and assessment of the resources and services offered to the program, highlighting strengths of the library's support. More importantly, engaging in the process can identify potential gaps and weaknesses that ultimately lead to improvements. Involvement with the review process also enhances the library profile on campus. Since Western Libraries has been involved in undergraduate program reviews from the beginning, we are strategically positioned to accommodate the dynamic nature of the process. In turn, this will ensure that moving forward, Western Libraries' review processes remain aligned with those of the University.

Our opening question asked how an academic library can most effectively participate and expand their contributions to program reviews at the institutional level. Our experience at the University of Western Ontario has been that it requires commitment and involvement at all levels of the library system. First, library administrators act as liaisons between the institution and the library. Secondly, librarians 
assume various roles from report creation to collaboration with program contacts. Finally, other library staff provides needed information gathering functions that inform the review document. In 2009, Western Libraries welcomed the challenges presented by the mandated undergraduate program review process. After four years with our process and resources for a variety of program reviews, our experience has been one of efficiency and success with respect to report creation. Added to this are the rewards of stronger ties between the university and the library, increased interaction with faculty at the program level and recognition of the library for its contributions to program review process.

\section{Disclosure Statement}

No conflicts of interest to report by any of the authors.

\footnotetext{
${ }^{1}$ Helge Salvesen, "Quality Assurance System for Higher Education in Norway - with Particular Reference to the Library Services," Liber Quarterly 16, no. 3/4 (2006). http://liber.library.uu.nl/publish/articles/000181/article.pdf (accessed October 21, 2011). ${ }^{2}$ Karin De Jager, "Towards Establishing an Integrated System of Quality Assurance in South African Higher Education Libraries," IFLA Journal 33, no. 2 (2007): 109-116.

${ }^{3}$ Felix N. Ubogu and Clare Walker, "Institutional Quality Audit: Experience of the University of the Witwatersrand Library" 11, 2007),
} 
http://archive.ifla.org/IV/ifla73/papers/131-Walker_Ubogu-en.pdf (accessed October 21, 2011).

${ }^{4}$ E. L. Adebayo, "Quality Assurance and the Implication for the Management of University Libraries in Nigeria," Library Philosophy and Practice (June, 2009), http://www.webpages.uidaho.edu/ mbolin/adebayo.htm (accessed October 21, 2011). ${ }^{5}$ Imogen Garner and Karen Tang, "A Quality Assurance and Benchmarking Framework in an Academic Library," IATUL Proceedings (2009): 150-156, http://www.iatul.org/doclibrary/public/Conf_Proceedings/2009/Garner-text.pdf (accessed October 21, 2011).

${ }^{6}$ Amos Lakos and Shelley Phipps, "Creating a Culture of Assessment: A Catalyst for Organizational Change," Portal 4, no. 3 (July, 2004): 345-361.

${ }^{7}$ Sharon A. Weiner, "Library Quality and Impact: Is there a Relationship between New Measures and Traditional Measures?" The Journal of Academic Librarianship 31, no. 5 (September 2005): 432-437.

${ }^{8}$ Laura Saunders, "Regional Accreditation Organizations' Treatment of Information Literacy: Definitions, Collaboration and Assessment," Journal of Academic Librarianship 33, no. 3 (2007): 317-326.

${ }^{9}$ V. L. Gregory, "The Academic Library in the Program Review Process." Collection Management 12, no. 3 (1990): 125-134.

${ }^{10}$ Ming-Ming Shen Kuo, Library Support for Academic Program Review--from an Evolving Local Model to what's Beyond. 1992, http://www.eric.ed.gov/PDFS/ED354886.pdf (accessed May 2, 2011). 
${ }^{11}$ Association of Universities and Colleges in Canada, Trends in Higher Education.

Volume 1, Enrolment. (Ottawa: AUCC, 2011), 70.

http://www.aucc.ca/_pdf/english/publications/trends-2011-vol1-enrolment-e.pdf (accessed October 21, 2011).

${ }^{12}$ Association of Universities and Colleges in Canada, Internationalizing Canadian Campuses. (Ottawa: AUCC, 2007), 27,

http://www.aucc.ca/_pdf/english/publications/aucc-scotia_web_e.pdf (accessed October 21, 2011).

${ }^{13}$ Abdou Ndoye and Michele A. Parker, "Creating and Sustaining a Culture of Assessment," Planning for Higher Education 38, no.2 (Jan-Mar 2010): 28-39.

${ }^{14}$ H. Hubball, N. Gold, J. Mighty, and J. Britnell, "Supporting the Implementation of Externally Generated Learning Outcomes and Learning-Centered Curriculum Development: An Integrated Framework," New Directions for Teaching and Learning 2007, no. 112 (2007): 93-105.

${ }^{15}$ Association of College and Research Libraries, "ACRL Joint Statement on Faculty Status of College and University Librarians,"

http://www.ala.org/ala/mgrps/divs/acrl/standards/jointstatementfaculty.cfm (accessed October 21, 2011).

${ }^{16}$ Gary W. White, "Managing the Accreditation Process: A Survey of Academic Business Librarians," Library Management 20, no. 8 (1999): 431-438.

${ }^{17}$ John M. Budd. "The Spellings Commission: Challenges to Higher Education and Academic Libraries.” portal: Libraries and the Academy, 7, no. 2 (2007): 137-146. 
${ }^{18}$ Krisellen Maloney, Kristin Antelman, Kenning Arlitsch, and John Butler. "Future Leaders' Views on Organizational Culture," College \& Research Libraries 71, no. 4 (2010): 322-345.

${ }^{19}$ Ibid.

${ }^{20}$ Guthrie, K., and Housewright., R. ., "Repackaging the Library: What do Faculty Think?" Journal of Library Administration. 51, no. (1) (2011): 77-104.

${ }^{21}$ Ibid.

${ }^{22}$ Carla J. Stoffle, and Cheryl Cuillier. "From Surviving to Thriving," Journal of Library Administration 51, no. 1 (2011): 130-155.

${ }^{23}$ Ibid.

${ }^{24}$ A. R. Albanese, "Deserted no More," Library Journal. 128, no. 7 (2003.): 34-36.

${ }^{25}$ Council on Quality Assurance, "Quality Assurance Framework," Ontario Council on Quality Assurance, (2011) http://www.cou.on.ca/related-sites/the-ontario-universitiescouncil-on-quality-assura/policies/pdfs/quality-assurance-framework---guide-may2011.aspx (accessed October 21, 2011).

26 “Library Documentation for Undergraduate Program Reviews - Guidelines and Template," http://www.lib.uwo.ca/files/aboutwl/UndergraduateProgramReview.pdf (accessed October 21, 2011).

${ }^{27}$ Ibid.

${ }^{28}$ Ibid., Excerpt from the template.

${ }^{29}$ Subcommittee on Undergraduate Frogram Review. "Guidelines for the appraisal of undergraduate programs", http://www.uwo.ca/univsec/handbook/general/Guidelines_for_the_Appraisal_of_Undergr aduate_Programs_OLD.pdf (accessed May 31, 2012). 
Undergraduate Program Review

23 of 23

${ }^{30}$ Kuo, 1992. 